\title{
The Concept of Emotional Labor in Health Sector
}

\author{
Ass. Prof. Dr. Ş. Didem Kaya \\ Faculty of Health Sciences of Necmettin Erbakan University, Konya, Turkey \\ Ass. Prof. Dr. Aydan Yüceler \\ Faculty of Health Sciences of Necmettin Erbakan University, Konya, Turkey
}

\section{Doi:10.5901/mjss.2013.v4n9p775}

\begin{abstract}
Emotions which are the feelings that humans experience, think and manage personally emerge by means of social interactions. Naturally emotions are significant in this process and for this reason it is desired to make use of emotions of employees as well and they are desired and expected to keep customer satisfaction at maximum level. Although emotion is abstract and very personal under normal conditions, today it has become almost a concrete product with economic value. Particularly in the health sectors the interest in using emotional labor grows increasingly in line with increasing significance of quality and use of emotional labor is deemed as one of the basic conditions of providing service quality. Emotional labor is generally accepted as one of the role requirements of the employee and expresses the efforts for exhibiting certain emotions requested by the sector or hiding certain emotions undesired by the sector. The purpose of this study is to specify the significance of the concept of emotional labor in the health sectors defined as the effort paid by the health employees who are in one-to-one communication with patients in the process of making their emotion exhibitions in conformity with the standards determined by health sectors.
\end{abstract}

Keywords: emotional labor, health sector, emotion

\section{Introduction}

Today upon the increase in the significance given to health, competition between health sectors has come to the agenda. In this case, the patients in the health sectors have been assessed as customer as well. In this context, the quality of the service provided in health sectors, customer satisfaction and ability of health sectors to realize their purposes become possible only through the efforts of health employees who are in one-to-one and usually face to face relations with those who are provided service. Naturally emotions become significant in this process and due to this fact it is desired and expected by the health sectors from the employees to use emotions of employees and keep customer satisfaction at the maximum level. Although emotion is abstract and very personal normally emotion, today it has become almost a concrete product with economic value. Now management of emotions in private life and management of emotions in professional life are discriminated from each other. Particularly in recent years in line with fast growth of the health sector the concept of "Emotional Labor" attracts the attention as an indispensible and common component of employees in health services as it is the case in other service fields.

\section{The Concept Of Emotional Labor}

Emotion is the basis of our social life. It is a phenomenon that makes us decide and that affects our decisions and even filters our perceptions (Lazanyi, 2010: 149). This phenomenon takes its place in professional life as well. It is possible to say that the action of working in a certain occupation is a significant determinant of the social existence of mankind and that it so represents an area where various emotions including love, hate, mercy, fear, disappointment, joy, guiltiness, jealousy are felt and revealed. Consequently when emotions are in question in professional life, very diversified research dimensions come to the agenda. However in addition to this, emotional components in the behaviors toward the customer or the person who is the addressee of the work performed or the emotional character of this behavior which is again an issue the significance of which has been increasing particularly in recent times are fields that try to examine the phenomenon of emotion in professional life with a different dimension. Providing forward of a certain emotional message to the other party through behaviors exhibited by the individual while performing his/her job is now accepted as one of the 
requirements of many jobs as a feature of the job role undertaken. In this mentioned field, emotions are discussed in the dimension of performing the job with a certain "emotion expression" and creating a feeling in the other party who is the addressee of the work performed (including customer, patients etc.) rather than the feelings felt toward the job, arising from the job or in connection with the job and this sort of an effort is called "emotional labor" (Seçer, 2005: 814).

The initial studies with regard to emotional labor were carried on by Arlie Russell Hochschild who suggested the concept for the first time (Basbug et.al, 2010: 256; Venkatesh and Balaji, 2013: 1). Hochschild defended in his book titled "The Managed Heart" which was published in 1983 that upon the increase of service sector and this requiring more oneto-one relationship with the customer, emotions were paid particular significance in the management process for the purpose of further increasing customer satisfaction and even emotions became commodities purchased and sold against money in this process. The principal issue in the process defined by Hochschild as "management of feelings in order to create mimical and physical shows that can be observed by everybody" is emotion management. When emotion management is performed against a certain fee it is named emotional labor (Secer, 2005: 825-26).

The concept of emotional labor is defined as the effort paid by the individual in exhibition by the individual of the emotions requested by the organization in mutual relation among individuals (Unlu and Yurur, 2011: 188). The effort here is for creating a positive situation and pleasure in perception among customers. In this case consumer satisfaction and service quality perception is increased and a positive impression is provided for the service providing organization. Since service work employees who are in direct contact with customers are positioned in the area between the customer and the organization and since they represent the sector toward the customer, the issue of how those employees behave becomes a critical point (D'Cruz and Noronha, 2012: 70).

According to Hochschild (1983), emotional labor is regulating emotions so as to enable them to be observed by others as required by the job and making face and body exhibitions for this purpose. Hochschild states that emotional labor is exhibited face to face and in the form of body gestures whereas later researchers following him (Basim and Begenirbas, 2012: 78) thought voice tone (on the phone) should be added to emotional labor in addition to this view (Kinman, 2009: 119). Namely, it is a tendency to synchronize body gestures, mimics and voice tone automatically and unwillingly and generally without noticing while one is in relation with people and thus it may be in question to feel emotions that are in harmony with and that supplement one another. It is suggested that this fact which may be expressed as feeling similar emotions with other people in certain cases and giving similar reactions or coming together at a certain emotional level shall lead to resembling comments on the situation and that the phenomenon of emotional infection shall emerge more probably and become effective when;

1. Interaction and devotion is high,

2. Emotion is exhibited by a person with high status and loved,

3. Emotion is harmonious with rules on which emotions are acceptable in the existing environment,

4. There are no strong anti-emotions,

5. There is confusion on the situation or the emotional attitude toward that situation (Secer, 2005: 820).

\section{Elements of Emotional Labor}

Emotional labor has three elements. Elements including emotion regulation, deep, superficial and sincere behavior and rules of emotion exhibition are deemed as basic elements of emotional labor (Secer, 2009: 220; Kinman, 2009: 119).

\subsection{Emotion Regulation}

Emotion regulation is defined as the process of affecting which emotions the individuals shall feel, when and how they will feel them and how they will reflect them and consequently expresses the change in behavioral and physiological reactions. In other words, while emotions indicate the reaction to any internal or external event, emotion regulation is the process of affecting the intensity, period of this reaction of individuals as well as reflecting it (Secer, 2009: 221).

\subsection{Superficial, Deeply and Sincere Behavior}

The behavior norms that demonstrate which emotion is convenient for any particular event are called exhibition rules. Employees shape their emotions as desired by the organization by obeying these rules named by Hochschild as feeling rules. This behavior of role exhibition by employees appears in two forms -by role playing or by trying to really feel those emotions. And those role behaviors are named as superficial role playing and deep role playing (Basbug et.al.: 260). 
Superficial behavior is pretention of an employee as he/she is feeling the emotion expected from him/her by making certain changes in his/her physical appearance (such as mimic, gesture or voice tone) although he/she may not really feel that emotions at that moment. This does not mean that the employee feels nothing but here the emotions exhibited (reflected) by the employee differs (Unlu and Yurur, 2011: 189).

Deeply behavior is the individuals' trial of really feeling the emotions that he/she should exhibit as required by behavior rules. Individuals try to change their internal emotions in order to be able to exhibit the emotions required by behavior rules. In deeply behavior there is the effort to make the behavior appear sincere beyond obeying those rules (Yurur et.al., 2011: 3828).

This does not take into account the situations of experiencing and exhibiting by the individual the emotion expected from him/her naturally and sincerely. Any service personnel may feel the emotion expected from him/her to be exhibited without having to pay any effort. A nurse having sympathy for an injured child does not need role playing. And for this reason feeling and reflection of the emotion expected from the employee to be exhibited sincerely is defined as sincere behavior (Unlu and Yurur, 2011: 188).

\subsection{Emotion Exhibition Rules}

Emotion exhibition rules are the rules according to which employees pay emotional labor following the emotion exhibition rules determined by the organization. Those rules which the organizations express they impose on their employees and manage them in this manner are named as feeling rules (Secer, 2009: 224).

Emotion exhibition rules become the behavior standards determined by organizations for performances of employees in different situations and under different conditions. The job requiring much diversified emotion exhibitions shall lead to the fact that employees shall need more emotion diversification and in this regard their emotional labor payment rates increase as well. The need for this emotion diversification causes the employees to have emotional discord (Basim and Begenirbas, 2012: 79).

\section{Emotional Labor in Health Sectors}

Health sector has certain peculiarities different from other sectors due to its fast growth and its inclusion high number of and much diversified health employees. And the most significant among those peculiarities is the situation of being in high interaction with patients who are in the position of customers. Considering customer satisfaction which is principal in service sectors as well, the quality of this face-to-face communication becomes very important. And health organization directors use various strategies for increasing the quality of customer-employee interaction. One of those strategies is the perceptions and attitudes exhibited by employees with regard to the service they provide. Namely emotional labor which is the requirement of mobilizing or oppressing of the employee his/her emotions in order to support physical appearance that creates a certain emotion situation in his/her customer.

Emotional labor is the situation of, planning and control and the effort of the employee for exhibiting the emotions expected from him/her in the process of exhibiting the emotions expected from the employee to exhibit during the process of interpersonal relations (Kinman, 2009: 118). In this case management of emotions in private life and management of emotions in professional life are discriminated from each other (Secer, 2005: 828). Because employees perform the mentioned emotion control against a certain fee since they use their emotional reactions as a part of their occupations. Their emotions are now a part of their occupations and their success in the workplace is closely related to how the use their emotions (Oral and Kose, 2011: 465). For this reason health sectors which want to make their service quality dependent on certain standards pay particular significance for creating and implementing emotional behavior rules (Oral and Kose, 2011: 469).

Competition increasing in line with the development in the health sectors made customers the focal points for the organization. During service provision health employees interact with customers more closely. This interaction increases the expectation from employees to include their emotional labor to their job and gives prominence to the role of emotional labor particularly in interactive service areas (Gungor, 2009: 168). Consequently the level of emotional labor of any health profession serving in the health sectors should be high. Among these, the role of the professions of doctors and nurses for example contains great emotional work, agreement, namely emotional labor (Mann and Cowburn, 2005: 154). Emotional labor in health sectors is rather a necessary phenomenon -for the patient- in health care cases. For example, emotional labor in health care has certain significance for patients with pain, panic, anxiety and fear experiences (Venkatesh and Balaji, 2013: 5). Because any patient having pain expects health employees to be good-humored, 
smiling and concerned in such a situation. Certainly this situation may have negative results on the employees as well. According to the findings of Maslach (1982) emotional labor is said to impose overdosed emotional load on health employees in the case of care requirement for patients (Lazanyi, 2010:151). According to Hochschild; the employees are required to pay certain effort in order to exhibit the emotions required by the job. And this may lead to burnout and job stress with the employees. Differently Ashforth and Humphrey suggest that in some cases employees may not need to pay conscious effort which may create stress for them in order to exhibit those behaviors, and that they may exhibit these sorts of behaviors without paying any effort within a routine. Consequently emotional labor has positive and negative influences of employees (Gungor, 2009: 179).

Today the point arrived at in the studies performed on emotional labor is the issue that emotions do exist in health sectors and have significance. It is an irrefutable fact that emotions are integrated parts of health employees working in the health sectors. There are studies discussing the significance of emotional labor on health employees in the health sectors (Mann, 2005; Mann and Cowburn, 2005; Brotheridge and Grandey, 2002; Lazanyi, 2010; Oral and Kose, 2011; Venkatesh and Balaji, 2013; Kose et.al., 2011). Under the light of those studies performed or to be performed in the future it is considered that expectations for emotional labor in health sectors began to become a part of organizational culture in time. Attempts to create and reinforce such a structure usually require directing and controlling the emotions of employees in professional life. In the end organizational culture becomes a structure oriented to control not only the behaviors but also the feelings of employees.

\section{Conclusion}

Emotions are now integrated parts of many occupations and jobs ranging from service sectors to professional occupations. This is the point reached in the studies performed in this issue as well. It is possible to base the significance and necessity of emotional labor on emotional bases of working environment. And the concept of emotional labor discussed as management of emotions may be defined as the effort paid for transforming the emotional reactions of employees working in one-to-one relation with customers as required his/her job into a form acceptable to the organization or for creating emotion exhibitions harmonious with the purposes of the organization.

Emotional labor is particularly revealed in jobs which require direct contact with people including health sectors, in jobs which require the employee to use his/her emotions to create an emotional situation with the other individual and in jobs which allow the organization to control the emotions of the employee. And in order to realize this, the employee uses his/her own emotions as an instrument. They exhibit behaviors of oppressing their emotions, exhibiting false emotion or over-exhibition of emotions depending on the situation. And the important point here is how the employee reflects his/her emotions to the customer rather than what the employee himself/herself feels. For example, the health employee should adjust his/her face mimics and body gestures and voice according to the situation of any patient applying to the health center. Namely he/she is expected to approach any patient with pain and panic more compassionately, more understandingly, cooler and more interested and not to reflect negative situations to the other party. They are required to exhibit consistent behaviors according to the situation all the time. It may be difficult for the individual to control emotions and to behave as expected by the organization particularly toward aggressive customers. In some cases the individuals are required to pay certain effort, namely emotional labor in order to obey behavior rules of the organization. Consequently the achievement of individuals obtained from this effort is related to how good they could manage emotions. Here the employees and directors are imposed great tasks and responsibilities.

\section{References}

Basım H. N., Begenirbaş M. (2012). Emotional Labor in Professional Life: A Scale Work, Journal of Management and Economy, 19 (1), 77-90.

Başbuğ, G., Ballı E., Oktuğ Z. (2010). The Effect of Emotional Labor on Job Satisfaction: A Study on Employees of Call Centers, Journal of Social Politics Conferences, 58 (1), 253-274.

Brotheridge C. M., Grandey A. A. (2002). Emotional Labor and Burnout: Comparing Two Perspectives of "People Work" Journal of Vocational Behavior, 60 (1), 17-39.

Brown S. (2010). The Effects of Emotional Labor on Wellbeing: Contrasts Between Health Care Settings, Murdoch University School of Psychology, The Degree of Doctor of Philosophy, Western Australia.

D'Cruz P., Noronha E., (Trans. F. Man) (2012). Performing Emotional Labor: Experiences of Indian Employees of Call Centers, Sakarya Journal of Economics, 1 (1), 95-121.

Güngör M. (2009). The Concept of Emotional Labor: Process and Results, Journal of Public Business, 11 (1), 167-184.

Kinman G. (2009). Emotional Labor and Strain in "front-line" Service Employees Does Mode of Delivery Matter? Journal of Managerial 
Psychology, 24 (2), 118-135.

Köse S., Oral L., Turesin H. (2011). A Research in Health Sector on the Relationship between Emotional Labor Behaviors and the Levels of Burnout in Employees, Journal of Faculty of Business Administration, 12 (2), 165-185.

Lazányi K. (2010). Emotional Labor and Its Consequences in Health-Care Setting, Proceedings of FIKUSZ '10 Symposium for Young Researchers, Budapest-Hungary, 149-156. http://kgk.uni-obuda.hu/fikusz

Mann S., Cowburn J. (2005). Emotional Labor and Stress within Mental Health Nursing, Journal of Psychiatric and Mental Health Nursing, 12 (2), 154-162.

Mann S. (2005) "A Health-Care Model of Emotional Labor: An Evaluation of the Literature and Development of A Model", Journal of Health Organization and Management, 19 (4/5), $304-317$.

Oral L., Köse S. (2011). A Research on the Relationship between Use of Emotional Labor by Doctors and Job Satisfaction and Burnout Levels, Journal of Suleyman Demirel University Faculty of Economic and Administrative Sciences, 16 (2), 463-492.

Seçer H. Ş. (2005). Emotions and Emotional Labor in Professional Life: An Assessment in terms of Sociology, Psychology and Organization Theory, Journal of Social Politics Conferences, 50 (1), 813-834.

Seçer H. Ş. (2009). Management of Emotions by the Organization: Emotional Labor-Theory Approaches, Operation and its Consequences (Edt. Keser A., Yılmaz G., Yürür Ş.) Behavior in Professional Life, Umuttepe Publications, Istanbul, 209-244.

Ünlü O., Yürür Ş. (2011). Emotional Labor and Task/Contextual Performance Relationship: A Research Service Sector Employees in Yalova, Journal of Erciyes University Faculty of Economic and Administrative Sciences, 190 (37), 183-207.

Venkatesh, J., Balajı J. (2013). The Health Cara Initiative for Emotional for Emotional Labors, International Journal of Education and Research, 1 (1), 1-9.

Yürür Ş., Gümüş M., Hamarat B. (2011). The Impact of Justice/Injustice Perceived in Employee-Customer Relations on Emotional Labor Behaviors, Journal of Yasar University, 23(6), 3826-3839. 